\title{
HAEMODYNAMIC EFFECTS OF DOBUTAMINE IN PULMONARY HYPERTENSION SECONDARY TO MITRAL STENOSIS - A DOPPLER ECHO STUDY
}

\author{
Cicy Bastian1, Raihanathul Misiriya Kamarudheen Jameela. ${ }^{2}$, N. Sudhaya Kumar³, S. Abdul khader ${ }^{4}$, Rajesh Gopalan Nair ${ }^{5}$
}

${ }^{1}$ Associate Professor, Department of Cardiology, Government T. D. Medical College, Alappuzha.

${ }^{2}$ Assistant Professor, Department of Cardiology, Government Medical College, Kottayam.

${ }^{3}$ Former Professor and HOD, Department of Cardiology, Government Medical College, Kottayam.

4 Professor, Department of Cardiology, Amala Institute of Medical Sciences, Thrissur.

5Associate Professor, Department of Cardiology, Government Medical College, Kozhikode.

\begin{abstract}
\section{BACKGROUND}

Significant Pulmonary Arterial Hypertension (PAH) is a common complication of mitral stenosis. The synthetic sympathomimetic amine dobutamine is a potent $\beta 1$ receptor agonist with some $\beta 2$ and $\alpha$ receptor agonistic properties. The net haemodynamic effects with dobutamine are a substantial increase in cardiac output with little or no change in arterial pressure and heart rate. Systemic and pulmonary vascular resistances decrease along with a modest decrease in pulmonary arterial wedge pressure.

The aim of this study was to analyse whether dobutamine infusion produces favourable effects on pulmonary vasculature in patients with Mitral Stenosis (MS).
\end{abstract}

\section{MATERIALS AND METHODS}

Patients with rheumatic heart disease, MS and PAH (right ventricular systolic pressure $\geq 60 \mathrm{mmHg}$ by Doppler echo study) were enrolled for the study. After screening, 15 patients were included in the study.

After obtaining baseline data, patients were given dobutamine infusion at a dose of $5 \mu \mathrm{gm} / \mathrm{kg} / \mathrm{mt}$ for 24 hours and the clinical and laboratory parameters were repeated on completion of dobutamine and on $5^{\text {th }}$ day.

\section{RESULTS}

Mean RVSP was $82 \mathrm{mmHg}$ in the basal state, which came down to $60 \mathrm{mmHg}$ with dobutamine for 24 hrs. The baseline mean mitral valve gradient was $14 \mathrm{mmHg}$ and it did not show significant variation with dobutamine. In patients with mitral stenosis and severe PAH, 24-hour dobutamine infusion resulted in a significant fall in PASP which was sustained for 5 days.

\section{CONCLUSION}

In patients with rheumatic MS and severe PAH, 24-hour infusion of dobutamine resulted in a significant fall in PASP which was sustained for 5 days. Patients undergoing mitral valve surgery may be given dobutamine infusion for 24 hours, which can bring down the PASP and reduce the operative risks.

\section{KEYWORDS}

Mitral Stenosis, Dobutamine, Pulmonary Arterial Hypertension.

HOW TO CITE THIS ARTICLE: Bastian C, Jameela RMK, Kumar NS, et al. Haemodynamic effects of dobutamine in pulmonary hypertension secondary to mitral stenosis - a Doppler echo study. J. Evolution Med. Dent. Sci. 2016;5(95):7022-7024, DOI: $10.14260 /$ jemds/2016/1588

\section{BACKGROUND}

The synthetic sympathomimetic amine dobutamine is a potent $\beta 1$ receptor agonist. However, it also possesses $\beta 2$ and $\alpha$ receptor agonist properties. ${ }^{1}$ It does not cause neuronal norepinephrine release. Dobutamine is a racemic mixture of $\mathrm{L}$ isomers and $\mathrm{D}$ isomers. The $\mathrm{L}$ isomer is an $\alpha 1$ receptor agonist and a relatively weak $\beta$ receptor agonist. The $\mathrm{D}$ isomer has pronounced effects on $\beta$ receptor and little effects on $\alpha$ receptors. B2 receptor mediated peripheral vasodilatation is partly counteracted by the concomitant activation of vascular $\alpha$ receptors. The positive inotropic effect of $\beta 1$ receptor is

Financial or Other, Competing Interest: None.

Submission 22-10-2016, Peer Review 14-11-2016,

Acceptance 21-11-2016, Published 28-11-2016.

Corresponding Author:

Dr. Cicy Bastian,

Associate Professor,

Department of Cardiology,

Government T D Medical College,

Alappuzha.

E-mail: cicybastian@hotmail.com

DOI: $10.14260 /$ jemds $/ 2016 / 1588$

\section{(c) (i) $\$$}

potentiated by simultaneous activation of the myocardial areceptors. Unlike dopamine, the positive inotropic effect of dobutamine is not related to norepinephrine stores. The usual net haemodynamic effects are a substantial increase in Cardiac Output (CO) with little or no change in arterial pressure and little or no increase in heart rate. ${ }^{2}$

Systemic vascular and pulmonary vascular resistances decrease along with a modest decrease in Pulmonary Arterial Wedge Pressure (PAWP). Although both dobutamine and dopamine increase CO, PAWP tends to increase with dopamine, whereas it decreases with dobutamine. Pulmonary artery pressure and Pulmonary Vascular Resistance (PVR) may also increase with dopamine. Adverse effects are less frequent with dobutamine than with other catecholamines. The elimination half-life is short - only 2 to 3 minutes. The usual dose of dobutamine is $2.5-10 \mu \mathrm{gms} / \mathrm{kg} / \mathrm{mt}$. An excess of $10 \mu \mathrm{gm} / \mathrm{kg} / \mathrm{mt}$ of dobutamine infusion is likely to induce undesirable tachycardia. The dose however should be titrated, starting with a lower infusion rate to obtain an adequate haemodynamic response. Dobutamine has been widely used to treat severe heart failure in the absence of profound hypotension, which is poorly responding to diuretics and 
vasodilators. Its positive inotropic and pulmonary vasodilating effects make it a promising drug in pulmonary embolism. ${ }^{3}$ Significant PAH is a fairly common complication of Mitral Stenosis (MS). It has a post-capillary component (passive PAH) and a precapillary component. Significant PAH is a high risk parameter for surgery (Valvotomy/valve replacement). So far there are no studies evaluating the role of dobutamine in reducing the pulmonary artery pressure in patients with MS and PAH. Hence, we analysed whether dobutamine infusion produces favourable effects on pulmonary vasculature in patients with MS.

The aim of the study was to study the haemodynamic effects of dobutamine in patients with mitral stenosis and significant Pulmonary Arterial Hypertension (PAH).

\section{MATERIALS AND METHODS}

Patients with Rheumatic Heart Disease (RHD), MS and PAH (RVSP $\geq 60 \mathrm{mmHg}$ by Doppler echo study) attending the Cardiology Department of Medical College Hospital, Kottayam were enrolled for the study. Those with recent worsening of heart failure, resting heart rate $\geq 90 / \mathrm{mt}$, organic tricuspid valve disease, RVOT gradient, other valvular lesions, hypertension and coronary artery disease were excluded. After screening, 15 patients were included in the study.

Digoxin, diuretics and other drugs were continued in patients whenever indicated.

Doppler echo examination was done in all patients using a Vingmed CFM 725 Doppler echo unit. Apart from routine data, stress was given to the following parametres. a) RVSP calculated from a properly aligned Tricuspid regurgitation (TR) jet using modified Bernoulli's equation.4,5,6 RVSP was calculated by adding the RA pressure (jugular venous pressure from the angle of LOUIS $+5 \mathrm{cms}$ ) to the TR gradient. b) $\mathrm{dP} / \mathrm{dT}$ of TR jet (to assess the RV systolic function)-7,8,9,10 on the Doppler signal of TR jet two points were taken - one corresponding to a velocity of $1 \mathrm{~m} / \mathrm{sec}$ (v1) and another to 3 $\mathrm{m} / \mathrm{sec}$ (v2). Doppler time between these two points was measured as dT. DP, i.e. the difference in pressure gradient between these two points was calculated by the formula $\mathrm{dP}=$ $4 \mathrm{v} 2^{2}-4 \mathrm{v} 1^{2} .4 \times 3^{2}-4 \mathrm{X} 1^{2}=36-4=32 \mathrm{mmHg}$ (a constant) (Figure 1) c) mitral valve gradient and d) LV systolic function.

Baseline clinical data and lab parametres were entered in a proforma. After obtaining the baseline data, patients were given dobutamine infusion at a rate of $5 \mu \mathrm{gm} / \mathrm{kg} / \mathrm{mt}$ for 24 hours and study was repeated on completion of dobutamine and on $5^{\text {th }}$ day.

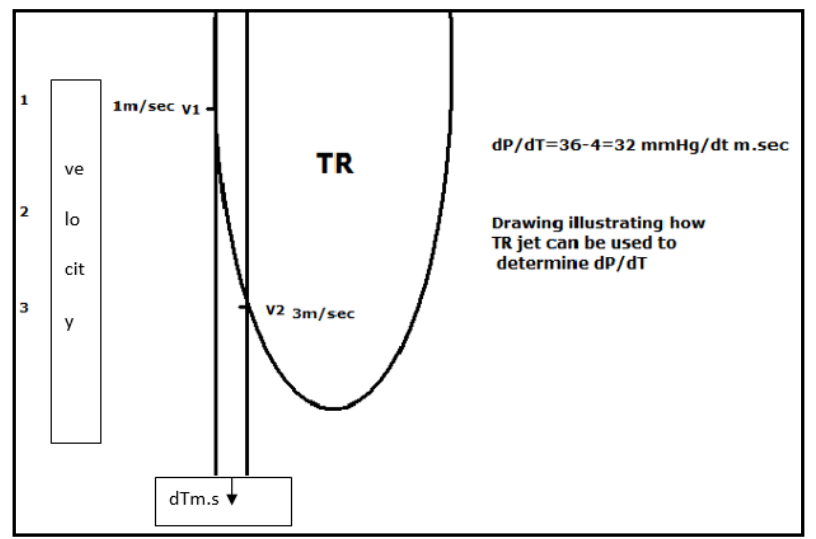

Figure 1

\section{Statistical Analysis}

All data were expressed as mean. Statistical comparisons were made by paired $T$ test. Statistical significance was assumed if the null hypothesis could be rejected at $\mathrm{P}=0.05$. All the statistical analysis was performed using SPSS for windows.

\section{RESULTS}

The baseline clinical characteristics of 15 patients are summarised in Table 1.

\begin{tabular}{|c|c|c|}
\hline Age & $34.73 \pm 11.64$ & \multirow{11}{*}{$\begin{array}{c}\text { HR - Heart Rate } \\
\text { BP - Blood Pressure } \\
\text { AF - Atrial Fibrillation } \\
\text { JVP - Jugular Venous } \\
\text { Pressure }\end{array}$} \\
\hline $\begin{array}{c}\text { Sex } \\
\text { Female/Male }\end{array}$ & $10 / 5$ & \\
\hline $\begin{array}{l}\text { NYHA class II } \\
\text { III }\end{array}$ & $\begin{array}{c}12 \\
3\end{array}$ & \\
\hline Palpitation & 11 & \\
\hline Angina & 0 & \\
\hline HR & $80 / \mathrm{mt}$ & \\
\hline BP (Systolic) & $110 \mathrm{mmHg}$ & \\
\hline $\mathrm{AF}$ & 10 & \\
\hline JVP & & \\
\hline Normal & 10 & \\
\hline Elevated & 5 & \\
\hline \multicolumn{3}{|c|}{ Table 1. Patient Characteristics } \\
\hline
\end{tabular}

Mean age of the patients was $34.73 \pm 11.64$ years; 5 patients had systemic venous congestion. Mean heart rate was $80 / \mathrm{mt}$. (Range of $70-90 / \mathrm{mt}$ ); 10 patients were in atrial fibrillation and 5 were in normal sinus rhythm.

\section{Doppler Echo Evaluation}

Mean Mitral Valve Area (MVA) was $0.86 \mathrm{~cm}^{2}$ with a range of $0.56-1.30 \mathrm{~cm}^{2}$. Mitral valve area obtained by planimetry and pressure half time method was $\leq 1 \mathrm{~cm}^{2}$ in 10 patients consistent with severe MS; 5 patients had moderate MS (MVA $1-1.5 \mathrm{~cm}^{2}$ ). Mitral Regurgitation (MR) was graded as Grade 0 - no MR, Grade 1 - mild MR, Grade 2 - mild-to-moderate MR, Grade 3 - moderate MR and Grade 4 - severe MR. None of the patients had moderate or severe MR (Table 2).

\begin{tabular}{|c|c|}
\hline & No. of Patients \\
\hline Mitral Valve Area & 10 \\
\hline$<1 \mathrm{~cm}^{2}$ & 5 \\
\hline $1-1.5 \mathrm{~cm}^{2}$ & 0 \\
\hline$>1.5 \mathrm{~cm}^{2}$ & 2 \\
\hline Mitral Regurgitation & 11 \\
\hline 0 = no MR & 2 \\
\hline 1 = mild MR & mild-to-moderate MR \\
\hline \multicolumn{2}{|c|}{ Table 2. Mitral Valve Doppler Echo Data } \\
\hline
\end{tabular}

\section{RVSP and RV Function}

Mean RVSP was $82 \mathrm{mmHg}$ (Range of 60 - 113) in the basal state, which came down to $60 \mathrm{mmHg}(19$ - 103) with dobutamine for 24 hours. Reduction in RVSP at 24 hours was observed in $12 / 15$ patients and the reduction was statistically significant $(\mathrm{p}<0.001) ; 6$ of these 12 patients showed a sustained fall at Day 5 . In the remaining six, there was marginal increment, but still the value was significantly lower than the basal RVSP, i.e. $66 \mathrm{mmHg}$ (Range 19 - 103) (p < 0.006). But when 24 hours and $5^{\text {th }}$ day RVSP were compared, the change was not significant $(p=0.120)$. See Figure 2 . 


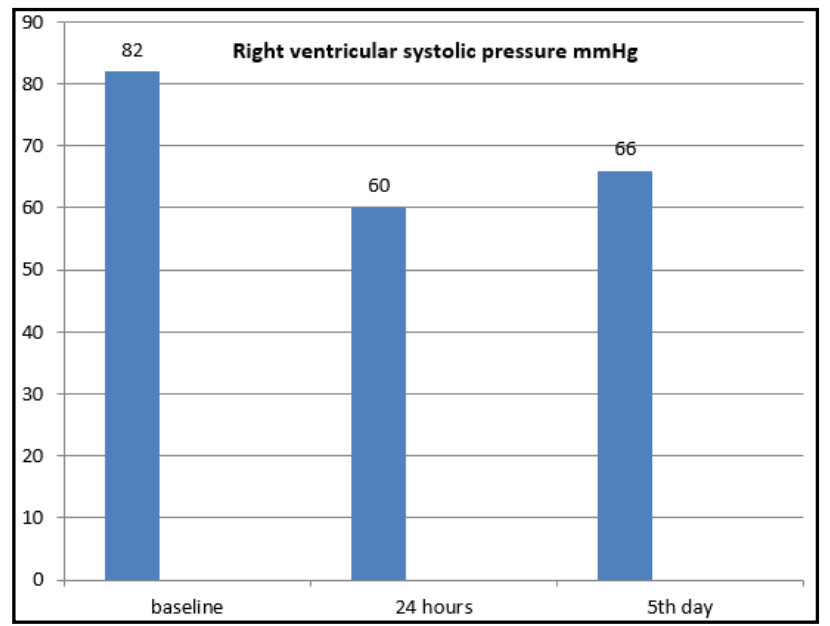

Mean dP/dT of TR jet at baseline was $744 \mathrm{mmHg} / \mathrm{second}$. At 24 hours it increased to 940 and on $5^{\text {th }}$ day it came down to 907. Even though there was improvement in RV function, the difference was not statistically significant $(p=0.280)$. The improvement was observed in 12/15 patients and of these 6 patients showed sustained improvement on $5^{\text {th }}$ day.

\section{Mitral Valve Gradient and LV Function}

The baseline mean mitral valve gradient was $14.358 \mathrm{mmHg}$ (Range 8-07-23.9) and it did not show significant variation with dobutamine. At 24 hours, mean mitral valve gradient was $13.736(\mathrm{p}=0.528)$ and on $5^{\text {th }}$ day it was $14.06(\mathrm{p}=0.533)$. There was no significant change in LVEF also (61.6 at baseline, 63.5 at 24 hours and 62.6 by $5^{\text {th }}$ day).

\section{DISCUSSION}

The results of this study demonstrate for the first time that dobutamine infusion brings down the RVSP in patients with mitral stenosis and pulmonary arterial hypertension (PAH). All patients in this study had moderate-to-severe mitral stenosis and PAH. The severity of PAH was assessed by Doppler echo evaluation. None of the patients had pulmonary valve gradient and hence this amounts to a fall in Pulmonary Artery Systolic Pressure (PASP). With dobutamine there was a statistically significant $27 \%$ reduction in RVSP. The reduction in RVSP was sustained at 24 hours also (20\% reduction from baseline). RV function showed improvement with dobutamine, though the difference was not statistically significant. Normal maximum $\mathrm{dP} / \mathrm{dT}$ in humans without haemodynamic abnormalities is $223-296 \mathrm{mmHg} / \mathrm{sec}$. Here the baseline values were high, which may be attributed to right ventricular hypertrophy compensating for elevated PASP. With dobutamine there was improvement in RV function as evidenced by increase in $\mathrm{RV} \mathrm{dP} / \mathrm{dT}$. Improvement in $\mathrm{RV} \mathrm{dP/dT}$ is likely to be due to the positive inotropic effect of dobutamine on failing RV. The improvement was sustained in $50 \%$ of patients on $5^{\text {th }}$ day, while others showed some attenuation of the inotropic responses. Still $\mathrm{dP} / \mathrm{dT}$ was higher than the baseline value, increase in gradient across the MV was not observed even with improved RV function and decreased PA pressure. RV should be able to pump more effectively with improved RV function and decreased PA pressure. This increment in pulmonary flow should raise the LA pressure and thus mitral valve gradient. But the expected increase in gradient was not observed across the mitral valve and patients did not show any symptomatic deterioration (Actually, there was symptomatic improvement). This indicates that the LA pressure did not significantly increase despite a possible increase in pulmonary flow. There can be two explanations for this phenomenon.

Venodilatory effects of dobutamine 2 increase in LA compliance. It is logical to expect that dobutamine has effect on blood vessels rather than on LA compliance. Hence, a pulmonary venodilatory effect may be responsible for the prevention of rise in LA pressure with dobutamine despite improvement in RV function and reduced PA pressure. LVEF at baseline was normal in all patients and there was no evidence for increase in LV Diastolic Pressure (LVDP) to bring down the gradient across the MV.

\section{CONCLUSION}

In patients with rheumatic MS and severe $\mathrm{PAH}, 24$-hour dobutamine infusion resulted in a significant fall in PASP, which was sustained for 5 days and an improvement in RV systolic function (Even though insignificant) without increasing MV gradient. For patients undergoing mitral valve surgery, increased PA pressure is a high risk factor. Such patients may be given dobutamine for 24-hour period, which can bring down the PASP and reduce the operative risks.

\section{REFERENCES}

1. Ruffolo RR, Spradlin TA, Pollock GD, et al. Alpha and beta adrenergic effects of the stereoisomers of dobutamine. J Pharmacol Exp Ther 1981;219(2):447-52.

2. Chatterjee J, Bendersky R, Parmley WW. Dobutamine in heart failure. Eur Heart J 1982;3:107.

3. Braunwald E. Heart disease: a text book of cardiovascular medicine. $5^{\text {th }}$ edn. Vol. ll. Philadelphia, PA: WB Saunders 1997:p. 1593.

4. Hatle L, Angelsen BA, Tromsolal A, et al. Non-invasive assessment of pressure drop in mitral stenosis by doppler ultrasound. Br Heart J 1978;40(2):131-140.

5. Hatle L, Angelsen BA, Tromsdal A. Non-invasive assessment of aortic stenosis by doppler ultrasound. $\mathrm{Br}$ Heart Journal 1980;43(3):284-92.

6. Requarth JA, Goldberg SJ, Vasko SD, et al. In vitro verification of doppler prediction of transvalve pressure gradient and orifice area in stenosis. Am J Cardiol 1984;53(9):1369-73.

7. Chen C, Rodriguez L, Guerrero JL, et al. Noninvasive estimation of the instantaneous first derivative of left ventricular pressure using continuous wave doppler echocardiography. Circulation 1991;83(6):2101-10.

8. Pai RG, Bansal RC, Shah P. Doppler-derived rate of left ventricular pressure rise. Its correlation with the postoperative left ventricular function in mitral regurgitation. Circulation 1990;82(2):514-20.

9. Bargiggia GS, Bertucci C, Recusani F, et al. A new method for estimating left ventricular $\mathrm{dP} / \mathrm{dT}$ by continuous wave doppler-echocardiography. Validation studies at cardiac catheterization. Circulation 1989;80(9):1287-92.

10. Chung N, Nishimura RA, Holmes DR, et al. Measurement of left ventricular $\mathrm{dp} / \mathrm{dt}$ by simultaneous doppler echocardiography and cardiac catheterization. J Am Soc Echocardiogr 1992;5(2):147-52. 